\title{
MODELLING OF THE PYROLYSIS ZONE OF A DOWNDRAFT GASIFICATION REACTOR
}

\author{
MÁRTA KÁKONYI ${ }^{* 1}$, ÁGNES BÁRKÁNYI ${ }^{1}$, TIBOR CHOVÁN ${ }^{1}$, AND SÁNDOR NÉMETH ${ }^{1}$ \\ ${ }^{1}$ Research Centre for Biochemical, Environmental and Chemical Engineering, University of Pannonia, \\ Egyetem u. 10, Veszprém, 8200, HUNGARY
}

\begin{abstract}
The increasing amount of municipal solid waste (MSW) is a growing challenge that current waste-treatment practices are having to face. Therefore, technologies that can prevent waste from ending up in landfill sites have come to the fore. One of the technologies that produces a valuable product from waste, namely synthesis gas, is gasification. The raw material of this technology is the so-called Refuse-Derived Fuel, which is made from MSW. Three separate zones are located in downdraft gasification reactors: the pyrolysis, oxidation and reduction zones. This work is concerned with the determination of kinetic parameters in the pyrolysis zone. It also discusses the estimation of the product composition of this zone, which defines the raw material of the following zone.
\end{abstract}

Keywords: gasification, modelling, waste, Refuse-Derived Fuel

\section{Introduction}

Management of the increasing quantity of municipal solid waste (MSW) is an ongoing issue. The majority of the waste ends up in landfill sites or is incinerated, leading to the emission of significant amounts of greenhouse gases. According to data from the European Union's Eurostat database [1], the EU27 countries produce in excess of 200 million tons of waste. The amount disposed of is continuously being reduced by separating recyclable and biodegradable materials. Although less and less waste is being dumped as landfill, landfill sites cannot accommodate waste being generated Therefore, the quantity of waste ending up in landfill sites is not reducing significantly. In 2019 the EU member states deposited 24 mass $\%$ of waste in landfill sites; that quantity was 53 million tons. In Hungary, this value was 51 mass $\%$, namely 1.9 million tons (Fig. 1).

As the waste deposited in landfill sites decomposes, methane is formed and released into the atmosphere as a result of a reduction in its volume through cracks in the soil layer used to cover the landfill. The global warming potential of methane $\left(\mathrm{CH}_{4}\right)$ is 25 times greater than that of carbon dioxide $\left(\mathrm{CO}_{2}\right)$ [2]. Therefore, the development of technologies that can prevent waste from ending up in landfill sites and further reduce greenhouse gas emissions through Carbon Capture, Utilization and Storage is justified. One such technology is gasification.

Different types of gasification reactors are available, namely moving bed, fluidized-bed, entrained-flow, rotary

\footnotetext{
*Correspondence: kakonyi.marta@mk.uni-pannon.hu
}

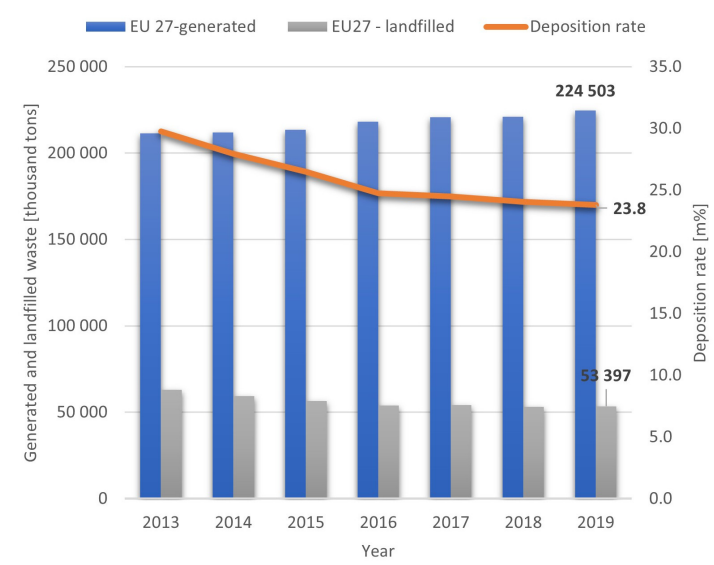

Figure 1: Generation of municipal solid waste and the amount deposited as landfill [1].

kiln and plasma gasifiers, which have been reviewed in Ref.[3,4]. Updraft and downdraft reactors are moving bed gasifiers. In the case of the former, the product gas travels in the opposite direction to the feedstock and leaves through the top of the reactor. Since the amount of tar contained in the product gas is higher than in the case of downdraft reactors, where the gas and feedstock flow in the same direction, the temperature of the effluent gas is higher. In fluidized-bed gasifiers, a bed material is used for the purpose of heat transfer and the raw material, which is fed into the reactor from the bottom, as well as the bed material are fluidized by air. The product gas contains a higher proportion of particles. The raw material of entrained-flow reactors is powdered, it along with 
air is fed into the reactor from the top. Rotary kiln gasifiers rotate around their axes to ensure the solid and gas phases mixture. Plasma reactors use copper or carbon electrodes and the raw material is decompozed down to the atomic level. Downdraft reactors are the most suitable for low tar content with high carbon conversion, as well as high hydrogen $\left(\mathrm{H}_{2}\right)$ and carbon monoxide (CO) content of the product. Its operating temperature and residence time meet the requirements of waste, namely its investment and operating costs are low.

The feedstock of downdraft reactors is fed from above while the air feed enters through the side of the reactor at a height slightly higher than halfway up the gasifier and is evenly distributed inside. Therefore, three separate zones can be formed. At the top, in an oxygen-deficient environment, is the pyrolysis zone, before air is introduced and the raw material partially burned in the oxidation zone to meet the energy demand of the endothermic reactions that take place in the other two zones. By proceeding along the length of the reactor, the reduction processes occur in the reduction zone after passing through the oxidation zone. Once the gas has passed through the reduction zone, it is extracted and the slag falls to the bottom of the reactor.

The aim of this work is to create a simple model that estimates the amount of gaseous components in the pyrolysis zone as a function of temperature based on the composition of the raw material and the amounts of the gases. Furthermore, such a model can be integrated into a model of a more complex gasification reactor. To calculate the amounts of the gases, the kinetic parameters of the pyrolysis zone are required, which were identified. The output of this zone is the raw material for the following oxidation zone.

\section{Identification of pyrolysis kinetic param- eters}

Various models using mainly biomass and cellulose feedstocks have been developed over the years to describe the pyrolysis zone. Some of them are suitable for molecular level studies, others are designed for particle-level studies and some are also applied to study equipment. Hameed at al. have compiled a detailed overview of them [5]. Since the pyrolysis zone is only one component of the reactor model, the less complex model referred to as the one-step kinetic model was chosen, which is written for the mass conversion as [6]

$$
\frac{\mathrm{d} m}{\mathrm{~d} t}=-k m(1-y)
$$

Here, $y$ is the conversion factor calculated by using the mass of raw material $\left(m_{\text {in }}\right)$, current mass ( $\left.m_{\text {actual }}\right)$, and the mass of the solid residue $\left(m_{\text {final }}\right)$ as [7]

$$
y=\frac{m_{\text {in }}-m_{\text {actual }}}{m_{\text {in }}-m_{\text {final }}} .
$$

The rate constant of the reaction, $k$, is defined by the Arrhenius equation

$$
k=A e^{\frac{-E_{\mathrm{a}}}{R T}},
$$

from which the unknown parameters $A$ and $E_{\mathrm{a}} / R$ can be determined. The amount of gas can be calculated from Eq. 1.

The parameters for cellulose and lignin (a mixture of paper, cardboard and wood)-hereinafter referred to as cellulose, plastic (a mixture of PE, PP and PET) as well as a $50-50 \mathrm{~m} \%$ blend of cellulose and plastic were identified separately. The kinetic parameters $\left(A\right.$ and $E_{\mathrm{a}} / R$ ) of both kinds of raw materials were unknown. Since the search space was smaller when identifying the parameters of pure raw materials, faster and more accurate results were achieved. The parameters were determined using the MATLAB R2019b program based on experimental data from the literature [8]. The effect of a catalyst on the decomposition of waste was investigated by thermogravimetry and mass spectrometry in a mass spectrometer. The inert atmosphere was composed of argon, while the masses of the samples were between 0.5 and $4 \mathrm{mg}$. Results in the absence of a catalyst are studied in this work. The heating rate of measurements was $20^{\circ} \mathrm{C} / \mathrm{min}$. The degradation of cellulose started at approximately 250 ${ }^{\circ} \mathrm{C}$, while that of plastic commenced at around $400{ }^{\circ} \mathrm{C}$ (Fig. 2).

In order to focus on the portion of the curves where the changes in mass were larger as well as the measured and calculated values deviated more, the temperature range was narrowed from $60-700{ }^{\circ} \mathrm{C}$ to $142-552$ ${ }^{\circ} \mathrm{C}$ for cellulose and to $369-531{ }^{\circ} \mathrm{C}$ for plastic. The $m \%$ of the residue was read from the graph. A global extrema searcher, NOMAD, was used in MATLAB to identify the parameters. The differential equation (Eq. 1) was solved using ode23s. The objective function to be minimized was the sum of the squares of the difference between the measured and calculated data for each temperature value:

$$
\min (f)=\sum_{T}\left(m \%_{\text {measured }}-m \%_{\text {calculated }}\right)^{2} .
$$

The identified parameters are shown in Table 1.

Once the kinetic parameters of the pure fractions had been identified, the mixture was calculated using these values. The change in total weight is the sum of the change in weight of the cellulose $\left(m_{\mathrm{c}}\right)$ and plastic $\left(m_{\mathrm{p}}\right)$ (Eq. 5). Furthermore, the $y$-factor (Eq. 2), the kinetic rate of the reaction (Eq. 3) and the mass conversion (Eq. 1)

Table 1: Identified parameters

\begin{tabular}{llll}
\hline & $\ln (A)$ & $E_{\mathrm{a}} / R[\mathrm{~K}]$ & $\begin{array}{l}\text { Correlation } \\
\text { coefficient }\end{array}$ \\
\hline Cellulose & 16.83 & 13540 & 0.915 \\
Plastic & 55.3 & 43502 & 0.765 \\
\hline
\end{tabular}




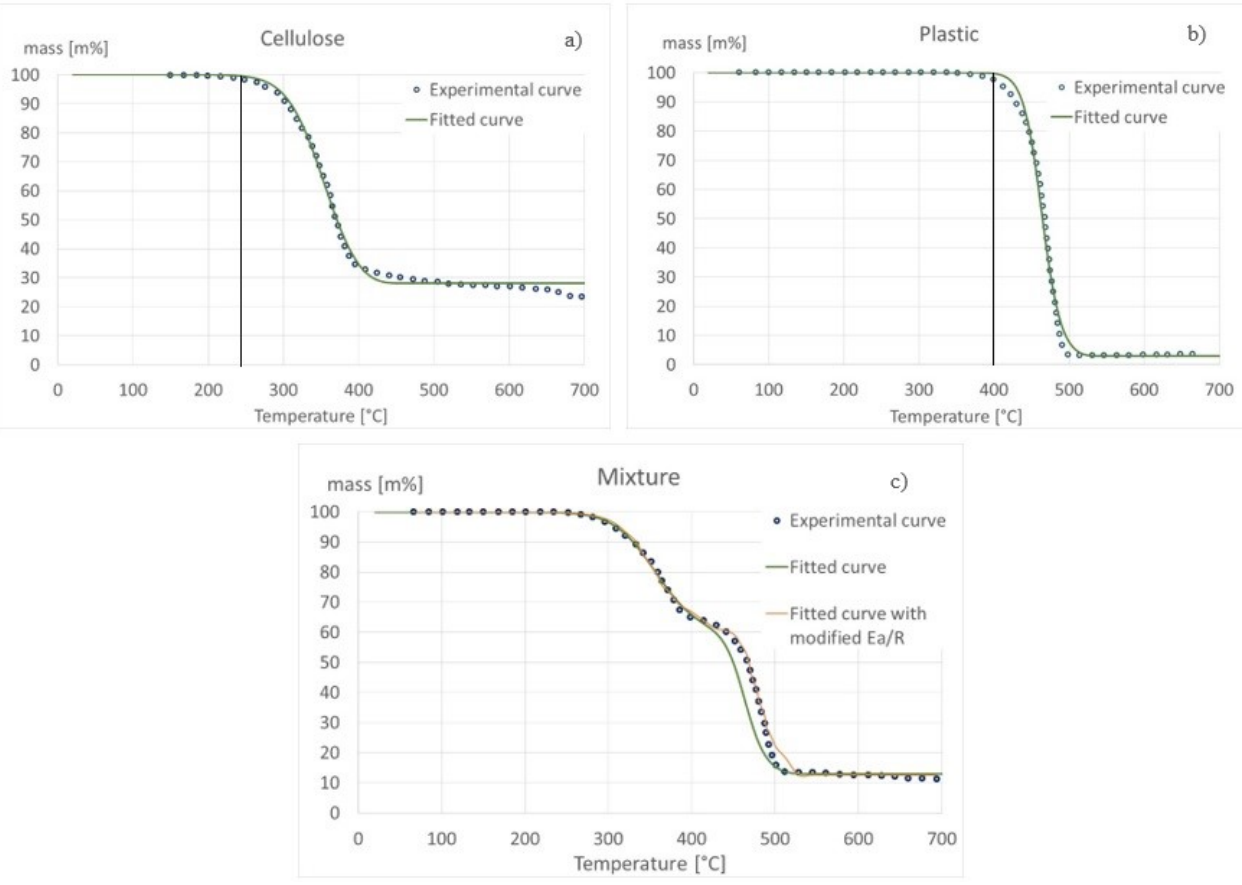

Figure 2: Measured [8] and simulated results using the identified parameters: a) cellulose, b) plastic, c) cellulose and plastic $50-50 \%$ mixture; o Experimental curve, - Fitted curve, - Fitted curve with modified $E_{\mathrm{a}} / R$, - degradation start

were calculated separately for both components:

$$
\frac{\mathrm{d} m}{\mathrm{~d} t}=\frac{\mathrm{d} m_{\mathrm{c}}}{\mathrm{d} t}+\frac{\mathrm{d} m_{\mathrm{p}}}{\mathrm{d} t}
$$

The results of the calculation using the applied model are shown in Fig. 2. The simulated decomposition curves of plastic (Fig. 2a) and cellulose (Fig. 2b) follow the experimental results well; the end of the curve deviates to a small extent caused by the decomposition of the lignin [9]. In the case of the mixture (Fig. 2c), a higher deviation in excess of $400{ }^{\circ} \mathrm{C}$ was observed. The decomposition of the cellulose commenced earlier at $250{ }^{\circ} \mathrm{C}$, while that of the plastic started at $400{ }^{\circ} \mathrm{C}$. The degradation of the plastic component started later. Although lignin begins to degrade at $400{ }^{\circ} \mathrm{C}$, which may affect the decomposition of plastic [8,9], the difference was not significant, so the degradation of the lignin was not treated separately from that of the cellulose.

Since the component of the Arrhenius equation corresponding to the activation energy depends on the temperature, the $E_{\mathrm{a}} / R$ value had to be modified. From the Arrhenius equation (Eq. 3), the value of $k$ was calculated along with the parameters before the kinetic parameters were recalculated by retaining the $k$ value. The parameter $E_{\mathrm{a}} / R$ of plastic changed, its new value was $44500 \mathrm{~K}$, the values of the other parameters remained unchanged as is presented in Table 1 . Using this new $E_{\mathrm{a}} / R$ number, the recalculated curve (depicted in orange) fitted better. Based on the one-step kinetic model, the mass of gas formed in the pyrolysis zone can be calculated. The disadvantage of this model is that it cannot determine the composition of the gas nor the quantities of its components. In the oxidation zone, since the products from the pyrolysis zone are partially oxidized, it is also necessary to quantify each gaseous component.

\section{Composition of the gas}

Pyrolysis gas consists of different components; the main components are carbon monoxide $(\mathrm{CO})$, hydrogen $\left(\mathrm{H}_{2}\right)$, carbon dioxide $\left(\mathrm{CO}_{2}\right)$, methane $\left(\mathrm{CH}_{4}\right)$, water $\left(\mathrm{H}_{2} \mathrm{O}\right)$, and tar. The exact molecular formula of tar is unknown, its formula is represented as $\mathrm{C}_{a} \mathrm{H}_{b} \mathrm{O}_{c}$. An extrema search was used to determine its composition.

\subsection{Composition of Refuse-Derived Fuel}

Some waste-treatment plants include mechanical biological treatment plants that produce Refuse-Derived Fuel (RDF) by filtering out and grinding MSW. In such plants, glass, metal as well as inert and biodegradable materials are removed, MSW is dried whilst being grinded and finally $3 \%$ of its original weight will be equal to the mass of the RDF. As the raw material of the reactor is RDF, the results of studies into the composition of RDF were collected and averaged Table 2. [10,11]

\subsection{Objective function and constraints}

Based on the composition, the constraints required for the extrema search can be determined. The total masses $\left(m_{j}\right)$ of each element, namely $\mathrm{C}, \mathrm{O}, \mathrm{H}, \mathrm{Cl}, \mathrm{S}$, and $\mathrm{N}$, were determined from Eq. 6. The mass of the impurities $\left(m_{\mathrm{Cl}}\right.$, $m_{\mathrm{S}}$ and $m_{\mathrm{N}}$ ) was subtracted from the total gas mass $\left(m_{\text {gas }}\right)$. The extrema finder searches for the minimum of the objective function, which is the absolute value of the 
Table 2: Average RDF composition

\begin{tabular}{ll}
\hline Proximate analysis [m\%] & \\
\hline Moisture content & 17.55 \\
Ash & 12.3 \\
Volatile matter & 63.18 \\
Fixed carbon & 6.97 \\
\hline Ultimate analysis of the dry basis [m\%] \\
\hline $\mathrm{C}$ & 40.83 \\
$\mathrm{H}$ & 5.36 \\
$\mathrm{O}$ & 37.08 \\
$\mathrm{~N}$ & 1.18 \\
$\mathrm{~S}$ & 0.29 \\
$\mathrm{Cl}$ & 0.34 \\
$\mathrm{Ash}$ & 14.92 \\
\hline
\end{tabular}

difference between the total mass of the gas and the sum of the mass of each gaseous component according to Eq. 7 , where $n_{i}$ denotes the moles of gaseous compounds and $M_{i}$ represents the molecular weight.

$$
\begin{gathered}
m_{j}=m_{\text {gas }} \frac{(m \%)_{j}}{100} \\
\min (f)=\operatorname{abs}\left(m_{\text {gas }}-\left(m_{\mathrm{Cl}}+m_{\mathrm{S}}+m_{\mathrm{N}}\right)-\sum_{i} M_{i} n_{i}\right)
\end{gathered}
$$

The total weight of each element should be equal to the sum of the weight of the same element in each compound. Due to the strength of the constraints, only a minimal error is permissible. The nonlinear constraints are

$$
0.01 \geq \frac{\operatorname{abs}\left[m_{\mathrm{C}}-M_{\mathrm{C}}\left(n_{\mathrm{CO}}+n_{\mathrm{CH}_{4}}+n_{\mathrm{CO}_{2}}+a n_{\mathrm{tar}}\right)\right]}{m_{\mathrm{C}}}
$$

$0.01 \geq \frac{\operatorname{abs}\left[m_{\mathrm{O}}-M_{\mathrm{O}}\left(n_{\mathrm{CO}}+2 n_{\mathrm{CO}_{2}}+n_{\mathrm{H}_{2} \mathrm{O}}+c n_{\mathrm{tar}}\right)\right]}{m_{\mathrm{O}}}$

$0.01 \geq \frac{\operatorname{abs}\left[m_{\mathrm{H}}-M_{\mathrm{H}}\left(4 n_{\mathrm{CH}_{4}}+2 n_{\mathrm{H}_{2} \mathrm{O}}+2 n_{\mathrm{H}_{2}}+b n_{\text {tar }}\right)\right]}{m_{\mathrm{H}}}$

The limits of the parameters $a, b$, and $c$ are determined based on the measurement of the tar composition [12,13]. The constraints of these parameters are

$$
12>a>6 ; \quad 24>b>6 ; \quad 6>c>0
$$

Empirical relationships $[14,15]$ were applied to the mass ratios of $\mathrm{CO}$ to $\mathrm{CO}_{2}$, and $\mathrm{CH}_{4}$ to $\mathrm{CO}_{2}$, which are temperature-dependent:

$$
y_{\mathrm{CO} / \mathrm{CO}_{2}}=\exp \left(1.8447896+\frac{7730313}{T}+\frac{5019898}{T}\right)
$$

Table 3: Lower and upper limits

\begin{tabular}{llllllll}
\hline Limit & $\mathrm{CO}_{2}$ & $\mathrm{H}_{2} \mathrm{O}$ & $\mathrm{H}_{2}$ & $\mathrm{C}_{a} \mathrm{H}_{b} \mathrm{O}_{c}$ & $a$ & $b$ & $c$ \\
\hline Lower [m\%] & 10 & 0 & 0.4 & 40 & 9 & 10 & 4 \\
Upper [m\%] & 25 & 10 & 0.7 & 95 & 11 & 20 & 6 \\
& & & & & & \\
$y_{\mathrm{CH}_{4} / \mathrm{CO}_{2}}=5 \times 10^{-16 T^{5.06}}$ & &
\end{tabular}

By measuring the composition of the pyrolysis gas $[8,16]$, the lower and upper limits were determined for the mass percent of components (Table 3 ). The $m \%$ limits were calculated from

$$
\begin{aligned}
& 0 \geq \frac{m \%_{\text {lower }}}{100}-\frac{n_{i} M_{i}}{m_{\text {gas }}-\left(m_{\mathrm{Cl}}+m_{\mathrm{S}}+m_{\mathrm{N}}\right)} \\
& 0 \geq \frac{n_{i} M_{i}}{m_{\text {gas }}-\left(m_{\mathrm{Cl}}+m_{\mathrm{S}}+m_{\mathrm{N}}\right)}-\frac{m \%_{\text {upper }}}{100}
\end{aligned}
$$

Using the kinetic parameters identified in the previous section, the batch pyrolysis was simulated for $250 \mathrm{~kg}$ of raw material with a moisture content of $17.55 \%$ as well as plastic and cellulose fractions of $50-50 \%$. During the process, the composition of the gas was calculated as a function of temperature based on the aforementioned equations. The heating rate which was used during identification was $20^{\circ} \mathrm{C} / \mathrm{min}$. The dry raw material was taken into account in the calculation. To reduce the calculation time, the composition was estimated every $20 \mathrm{~s}$ so the total simulation time was 3600 s. In each step, the starting point of the extrema search was the result of the calculation during the previous step. The results of the simulation are shown in Fig. 3 and Table 4. Above $500{ }^{\circ} \mathrm{C}$, the tar began to decompose and the amount of $\mathrm{CO}$ increased compared to that of $\mathrm{CO}_{2}$.

\section{Conclusions}

The aim of this work was to develop a relatively simple model of the pyrolysis zone of a downdraft gasification reactor to estimate its kinetic parameters and based on these propose a methodology to determine the amount of gaseous components generated. The kinetic parameters of the pyrolysis zone were determined by an extrema finder and the calculated values fit well with the experimental results found in the literature. With the help of the proposed model, the kinetic parameters can be identified for any new raw material and heating rate. The method applied to determine the composition of gaseous components is suitable for estimating the quantity of components as a function of temperature based on the elemental composition of the raw material. The one-step kinetic model using a simple calculation of the gas composition can be easily applied to describe the pyrolysis zone of the $\mathrm{RDF}$ gasification reactor and even integrated into a more complex model of a gasification system because of the low computational capacity required. 

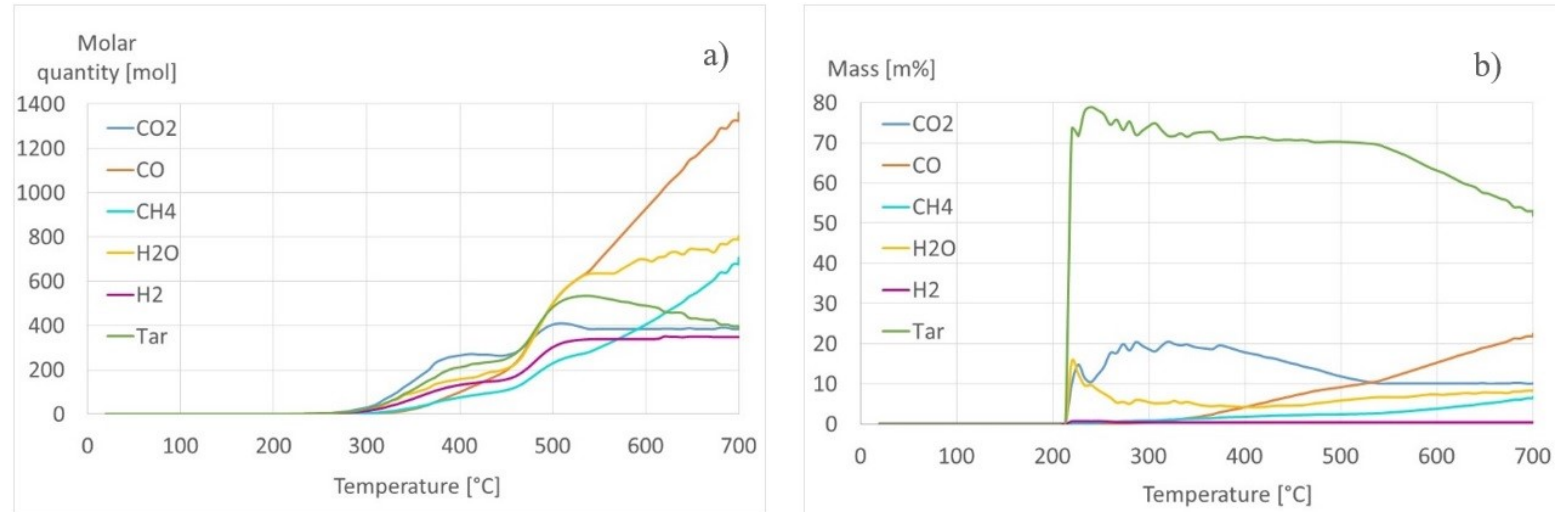

Figure 3: Evolution of molar quantity a) and weight percentage b) as a function of temperature

Table 4: Gas composition as a function of temperature

\begin{tabular}{lcccccc}
\hline Temperature $\left[{ }^{\circ} \mathrm{C}\right]$ & 200 & 300 & 400 & 500 & 600 & 700 \\
\hline Molar quantity [mol] & & & & & & \\
$\mathrm{CO}_{2}$ & 0 & 29.2 & 266.1 & 406.5 & 386.5 & 390.2 \\
$\mathrm{CO}$ & 0 & 1.2 & 98.9 & 499.7 & 927.7 & 1361.5 \\
$\mathrm{CH}_{4}$ & 0 & 3.6 & 74.7 & 229.9 & 404.6 & 707.1 \\
$\mathrm{H}_{2} \mathrm{O}$ & 0 & 21.2 & 157 & 499.8 & 696.8 & 804.4 \\
$\mathrm{H}_{2}$ & 0 & 14 & 132 & 304.2 & 340.3 & 349.6 \\
$\mathrm{Tar}$ & 0 & 23.6 & 211 & 483.1 & 489.8 & 387.1 \\
$a$ & 0 & 9.1 & 9.2 & 9 & 9 & 9.5 \\
$b$ & 0 & 17.3 & 18.2 & 17.3 & 17.3 & 18.2 \\
$c$ & 0 & 5.6 & 5.9 & 6 & 5.9 & 6 \\
\hline $\mathrm{Mass}[m \%]$ & & & & & & \\
$\mathrm{CO}$ & 0 & 18.6 & 17.8 & 11.8 & 10 & 10.1 \\
$\mathrm{CO}_{\mathrm{CH}}$ & 0 & 0.5 & 4.2 & 9.2 & 15.3 & 22.4 \\
$\mathrm{H}_{2} \mathrm{O}$ & 0 & 0.8 & 1.8 & 2.4 & 3.8 & 6.7 \\
$\mathrm{H}_{2}$ & 0 & 5.5 & 4.3 & 5.9 & 7.4 & 8.5 \\
Tar & 0 & 0.4 & 0.4 & 0.4 & 0.4 & 0.4 \\
\hline & 0 & 74.2 & 71.5 & 70.3 & 63.1 & 51.9 \\
\hline
\end{tabular}

\section{Acknowledgements}

This work was supported by the TKP2020-NKA-10 project financed under the 2020-4.1.1-TKP2020 Thematic Excellence Programme by the National Research, Development and Innovation Fund of Hungary.

\section{REFERENCES}

[1] Eustat-Municipal Waste by Waste Management, Date of save: 2021. 04. 07. https://ec.europa.eu/eurostat

[2] IPCC: Fourth Assessment Report, 2006

[3] Molino, A.; Chianese, S.; Musmarra, D.: Biomass gasification technology: The state of the art overview, J. Energy Chem., 2016, 25(1), 10-25 DOI: 10.1016/j.jechem.2015.11.005

[4] Kumar, A.; Jones, D.D.; Hanna, M.A.: Thermochemical biomass gasification: a review of the current status of the technology, Energies, 2009, 2(3), 556-581 DOI: 10.3390/en20300556

[5] Hameed, S.; Sharma, A.; Pareek, V.; Wu, H.; Yu, Y.: A review on biomass pyrolysis models: Kinetic, net- work and mechanistic models, Biomass Bioenerg., 2019, 123, 104-122 DOI: 10.1016/j.biombioe.2019.02.008

[6] Varhegyi, G.; Jakab, E.; Antal Jr, M.J.: Is the Broido-Shafizadeh model for cellulose pyrolysis true?, Energy Fuels, 1994, 8(6), 1345-1352 DOI: 10.1021/ef00048a025

[7] Faravelli, T.; Frassoldati, A.; Hemings, E.B.; Ranzi, E.: Multistep Kinetic Model of Biomass Pyrolysis, in Cleaner Combustion, 2013, 111-139, http://link.springer.com

[8] Sebestyén, Z.; Barta-Rajnai, E.; Bozi, J.; Blazsó, M.; Jakab, E.; Miskolczi, N.; Sója, J.; Czégény, Z.: Thermo-catalytic pyrolysis of biomass and plastic mixtures using HZSM-5, Appl. Energy, 2017, 207, 114-122 DOI: 10.1016/j.apenergy.2017.06.032

[9] Grammelis, P.; Basinas, P.; Malliopoulou, A.; Sakellaropoulos, G.: Pyrolysis kinetics and combustion characteristics of waste recovered fuels, Fuel, 2009, 88(1), 195-205 DOI: 10.1016/j.fuel.2008.02.002

[10] Vounatsos, P.; Atsonios, K.; Itskos, G.; Agraniotis, M.; Grammelis, P.; Kakaras, E.: Classification 
of refuse derived fuel (RDF) and model development of a novel thermal utilization concept through air-gasification, Waste Biomass Valori., 2016, 7(5), 1297-1308 DOI: 10.1007/s12649-016-9520-6

[11] Phyllis2: The results of RDF composition studies were collected and averaged, Date of save 2020.12.11. https://phyllis.nl

[12] Blanco, P.H.; Wu, C.; Onwudili, J.A.; Williams, P.T.: Characterization of tar from the pyrolysis/gasification of refuse derived fuel: influence of process parameters and catalysis, Energy Fuels, 2012, 26(4), 2107-2115 DOI: 10.1021/ef300031j

[13] Ponzio, A.; Kalisz, S.; Blasiak, W.: Effect of operating conditions on tar and gas composition in high temperature air/steam gasification (HTAG) of plas- tic containing waste, Fuel Process. Technol., 2006, 87(3), 223-233 DOI: 10.1016/j.fuproc.2005.08.002

[14] Salem, A.M.; Paul, M.C.: An integrated kinetic model for downdraft gasifier based on a novel approach that optimises the reduction zone of gasifier, Biomass Bioenerg., 2018, 109, 172-181 DOI: 10.1016/j.biombioe.2017.12.030

[15] Sharma, A.K.: Modeling and simulation of a downdraft biomass gasifier 1. Model development and validation, Energy Convers. Manag., 2011, 52(2), 1386-1396 DOI: 10.1016/j.enconman.2010.10.001

[16] Efika, E.C.; Onwudili, J.A.; Williams, P.T.: Products from the high temperature pyrolysis of RDF at slow and rapid heating rates, J. Anal. Appl. Pyrolysis, 2015, 112, 14-22 DOI: 10.1016/j.jaap.2015.01.004 